\title{
The Age Old Misnomer: Oral Pyogenic Granuloma-A Case Report
}

\section{Dr. Geon Pauly*, Roopashri Rajesh Kashyap, Raghavendra Kini, Prasanna Kumar Rao, Gowri P Bhandarkar, and Surashmi PT}

Department of Oral Medicine and Radiology, A J Institute of Dental Sciences, India

Received: 恝 September 07, 2018; Published: 眥 September 12, 2018

*Corresponding author: Geon Pauly N, Department of Oral Medicine and Radiology, AJ Institute of Dental Sciences, Karnataka, India

\begin{abstract}
An essential diagnostic challenge often faced by oral physicians is diagnosing soft tissue enlargements of the oral cavity. The fundamental reason being there are a diverse group of pathologic processes that can produce such lesions. Any intra-oral enlargement seen may represent a variation of normal anatomic structures, developmental anomalies, inflammation, cysts or even a neoplasm. Confined to these are the group of reactive hyperplasias of the oral cavity, which develop in response to a chronic, recurring tissue injury that stimulates an exuberant or excessive tissue repair response. Pyogenic granuloma comes under as one of the most common entities responsible for causing soft tissue enlargements.
\end{abstract}

Keywords: Pyogenic Granuloma; Oral Cavity; Inflammatory Hyperplasia; Misnomer

\section{Introduction}

Pyogenic granuloma is one of the inflammatory hyperplasia seen in the oral cavity [1]. It is not associated with pus as its name suggests and histologically it resembles an angiomatous lesion rather than a granulomatous lesion [2]. Thus, the term is a misnomer and in reality arises in response to various stimuli such as low-grade local irritation, traumatic injury or hormonal factors
$[1,2]$. Typically, it presents as an exuberant, red painless mass that easily bleeds, ulcerates and grows rapidly and is frequently seen on the gingiva [3]. Surgical excision with linear closure allows histologic examination of the tissue. It also has the lowest rate of recurrence and is therefore the treatment of choice [4]. Hereby, we present a case of a 21-year-old male patient who presented with a growth on the gingiva and bleeding in upper front teeth region.

\section{Case Report}
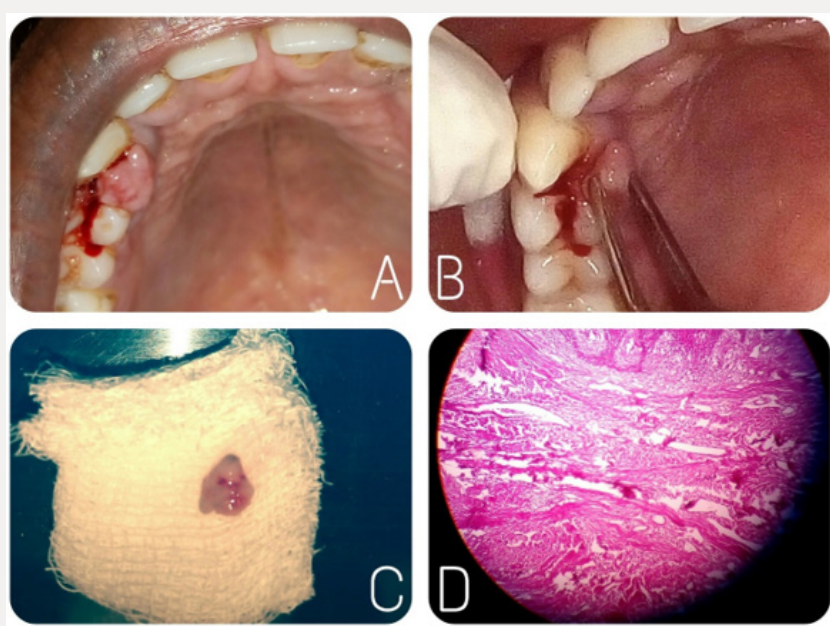

Figure 1: A - Growth on the palatal aspect of 13,14. B - Pedunculated and bleeding on provocation. C - Excised specimen. D Histological section. 
A 21-year-old male patient reported with a growth behind the teeth in the upper front tooth region. The growth had first appeared two months back and had been slow growing to attain the present size. The patient gave a history of mild intermittent pain which aggravated on chewing food and was concerned about the compromised esthetics. His medical, dental and family histories were non-contributory. He was an avid pan and gutkha chewers since three years. On examination an exophytic growth on the palatal aspect of upper right canine between the right canine and first premolar was seen. The growth was irregular in shape, about one $\mathrm{cm}$ in size, smooth and lobulated (Figure 1A). It was pedunculated, soft in consistency and there was bleeding on provocation (Figure 1B). Based on the clinical examination we came to a provisional diagnosis of pyogenic granuloma. An excisional biopsy was carried out under local anesthesia (Figure 1C) and the report confirmed the same (Figure 1D). The patient was recalled after one, three and six months and it showed no recurrence of the growth.

\section{Discussion}

In 1844, Hullihen [5] described the first case of pyogenic granuloma in English literature. In 1897, pyogenic granuloma in man was described as "botryomycosis hominis." Hartzell [6] in 1904 is credited with giving the current term of "pyogenic granuloma" or "granuloma pyogenicum." It was also called a Crocker and Hartzell's disease [6]. Angelopoulos histologically described it as "hemangiomatous granuloma" due to the presence of numerous blood vessels and the inflammatory nature of the lesion [7]. Cawson et al. [8] in dermatologic literature have described it as "granuloma telangiectacticum" due to the presence of numerous blood vessels seen in histological sections. They described two forms of pyogenic granulomas, the lobular capillary hemangioma ( $\mathrm{LCH})$ and the non-lobular capillary hemangioma (non-LCH) [2]. The exact etiopathogenesis remains unknown, although contributory factors include trauma, inflammation and infectious agents. Female sex hormones may also play a role as the condition occurs at increased frequency in pregnant women and in those who use oral contraceptive pills. It is believed that trauma and female sex hormones enhance expression of angiogenic factors such as basic fibroblast growth factor (bFGF) and vascular endothelial growth factor (VEGF) which will lead to evolution of the pyogenic granuloma. Medications such as isotretinoin, acitretin, cyclosporine, lamivudine, docetaxel, imatinib, and indinavir may also be contributing factors. Infections such as caused by herpes simplex type-I and Epstein-Barr virus have also been incriminated [4]. Oral pyogenic granulomas occur in all age groups, children to older adult, but are more frequently encountered in females in their second decade due to the increased levels of circulating hormones estrogen and progesterone [2]. Pyogenic granuloma of the oral cavity appears as an elevated, smooth or exophytic, sessile or pedunculated growth covered with red hemorrhagic and compressible erythematous papules, which appear lobulated and warty showing ulcerations and covered by yellow fibrinous membrane [9]. The color varies from red, reddish purple to pink depending on the vascularity of the growth. The gingiva, especially the marginal gingivais affected more than the alveolar part $[10,11]$. Besides the gingiva it is also noticed on the lips, tongue or buccal mucosa, affecting the maxilla more than the mandible, the anterior region than the posterior with the buccal surfaces being affected more than the lingual surfaces. The size varies from a few millimeters to several centimeters and it is usually slow growing, asymptomatic, painless growth, but at times it grows rapidly $[9,10]$.

Differential diagnosis of pyogenic granuloma includes peripheral giant cell granuloma, peripheral ossifying fibroma, fibroma, peripheral odontogenic fibroma, hemangioma, conventional granulation tissue, hyperplastic gingival inflammation, Kaposi's sarcoma, bacillary angiomatosis, angiosarcoma, and non Hodgkin's lymphoma [12]. Radiographic findings are usually absent. However, Angelopoulos [7] concluded that in some cases long standing gingival pyogenic granulomas caused localized alveolar bone resorption [12]. Histologically, the lesion appears as a lobular proliferation of capillaries with each lobule containing a central feeder vessel surrounded by aggregates of capillaries [4]. The lobules are separated by a fibro-myxoid stroma. In those lesions that are undergoing regression, there may be extensive fibrosis $[4,13]$. For gingival lesions, excising the lesion down to the periosteum and scaling adjacent teeth to remove any calculus and plaque that may be a source of continuing irritation is recommended. Although surgical excision is the considered the treatment of choice, management of pyogenic granuloma depends on the severity of symptoms [3,14]. If the lesion is small, painless and free of bleeding, clinical observation and follow up are advised. Other treatment modalities include laser surgery, electrodessication. Injection of absolute ethanol, sodium tetradecylsulfate (sclerotherapy) and corticosteroids have also been tried with successful results in cases with recurrent lesions [15]. The prognosis is usually excellent, and the lesion usually does not recur unless inadequately removed. The recurrence rate is higher for pyogenic granulomas removed during pregnancy. Other possible reasons for recurrence include; incomplete excision, failure to remove etiologic factors, or due to re-injury to the area, making follow up necessary $[14,16]$.

\section{Conclusion}

Despite the fact that pyogenic granuloma is a non-neoplastic growth in the oral cavity; a proper diagnosis, timely prevention and appropriate management are of utmost importance, careful diagnosis is essential to differentiate this lesion from other vascular lesions. Surgical excision of the growth, along with curettage should be done to prevent recurrences of this common lesion. And though the term pyogenic granuloma is still the used terminology of choice, it is a well-known fact that it is not associated with pus and histologically it resembles an angiomatous lesion rather than granulomatous lesion. Thus, it indicates that despite the term "pyogenic granuloma" being a misnomer, sometimes the good old quote - "Change is the only constant" gets a reality check as clearly time wants this terminology to stay in the literature books despite it lacking any accuracy at all. 


\section{References}

1. Jafarzadeh H, Sanatkhani M, Mohtasham N (2006) Oral pyogenic granuloma: A review. J Oral Sci 48(4): 167-175.

2. Gomes SR, Shakir QJ, Thaker PV, TavadiaJK (2013) Pyogenic granuloma of the gingiva: A misnomer? - A case reportand review of literature. J Indian Soc Periodontol 17(4): 514-519.

3. Kurian B, Sasirekha E, Ebenezer (2014) Pyogenic granuloma-A case report and review. International Journal of Dental Sciences and Research 2(3): 66-68.

4. Leung AKC, Barankin B, Hon KL (2014) Pyogenic granuloma. Clinics Mother Child Health 11: 106.

5. Hullihen SP (1844) Case of aneurism by anastomosis of the superior maxillae. Am J Dent Sci; 4: 160-2.

6. Hartzell MB (1904) Granuloma pyogenicum. J Cutan Dis Syph 22: 520525.

7. Angelopoulos AP (1971) Pyogenic granuloma of the oral cavity: Statistical analysis of its clinical features. J Oral Surg 29(12): 840-847.

8. Cawson RA, Binnie WH, Speight PM, Barrett AW, Wright JM (1998) Lucas pathology of tumors of oral tissues. Missouri: Mosby 5: 252-254.
9. Neville BW, Damm DD, Allen CM, Bouquot JE (2002) Oral and maxillofacial surgery ( $2^{\text {nd }}$ edn.). Philadelphia: Saunders, USA 2: 447-449.

10. Regezi JA, Sciubba JJ, Jordan RC (2003) Oral pathology: Clinical pathological considerations ( $4^{\text {th }}$ edn.) Philadelphia: WB Saunders 4: 115-116.

11. Mubeen K,Vijaylakshmi KR, AbhishekRP (2011) Oral pyogenicgranuloma with mandible involvement: An unusual presentation. J Dent Oral Hyg 3(1): 6-9.

12. Kamal R, Dahiya P, Puri A (2012) Oral pyogenic granuloma:Various concepts of etiopathogenesis. J Oral Maxillofac Pathol 16(1): 79-82.

13. Yazdanian S, Parish LC, Lambert PC, Lambert WC (2013) Pyogenicgranuloma: An enigma within a paradox or a solution in search of a problem. Skinmed 11(2): 74-77.

14. Ichimaya M, Yoshikawa Y, Hamamoto Y, Muto M (2004) Successful treatment of pyogenic granuloma with absolute alcohol. J Dermatol 31(4): 342-344

15. Moon SE, Hwang EJ, Cho KH (2005) Treatment of pyogenic granuloma by sodium tetradecyl sulphate sclerotherapy. Arch Dermatol 141(5): 644-646.

16. Venugopal S, KS Shobha, TD Netravathi (2010) Pyogenic granuloma-A case report. Journal of Dental Sciences \& Research 1(1): 80-85.

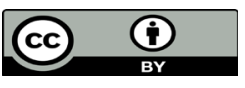

This work is licensed under Creative Commons Attribution 4.0 License

To Submit Your Article Click Here: Submit Article

DOI: 10.32474/MADOHC.2018.03.000157

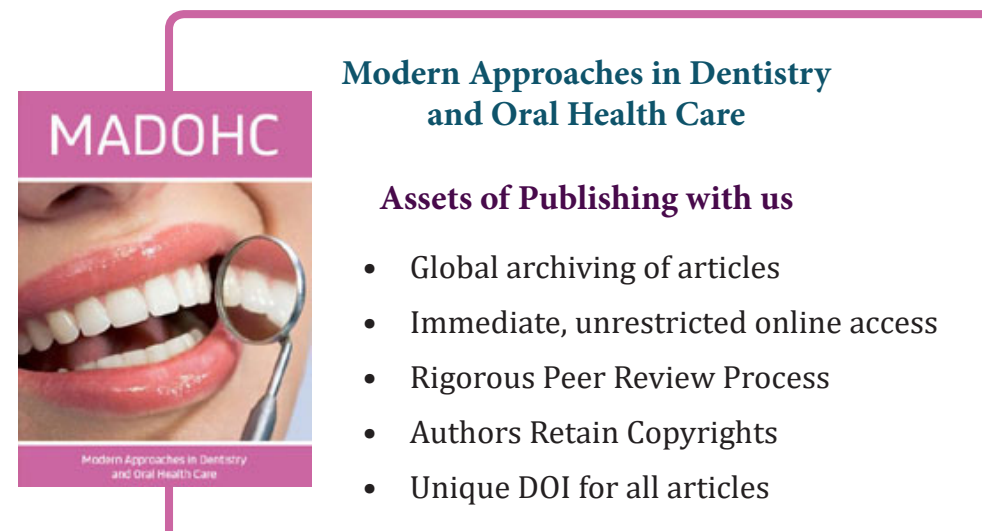

